\title{
An Experimental Study on Solute Transport in One-Dimensional Clay Soil Columns
}

\author{
Muhammad Zaheer, ${ }^{1}$ Zhang Wen, ${ }^{1}$ Hongbin Zhan, ${ }^{1,2}$ Xiaolian Chen, ${ }^{1}$ and Menggui Jin ${ }^{1}$ \\ ${ }^{1}$ School of Environmental Studies, China University of Geosciences, Wuhan, Hubei 430074, China \\ ${ }^{2}$ Department of Geology and Geophysics, Texas AઐM University, College Station, TX 77843-3115, USA \\ Correspondence should be addressed to Zhang Wen; wenz@cug.edu.cn
}

Received 21 March 2017; Accepted 8 May 2017; Published 14 June 2017

Academic Editor: Yingfang Zhou

Copyright ( 2017 Muhammad Zaheer et al. This is an open access article distributed under the Creative Commons Attribution License, which permits unrestricted use, distribution, and reproduction in any medium, provided the original work is properly cited.

\begin{abstract}
Solute transport in low-permeability media such as clay has not been studied carefully up to present, and we are often unclear what the proper governing law is for describing the transport process in such media. In this study, we composed and analyzed the breakthrough curve (BTC) data and the development of leaching in one-dimensional solute transport experiments in lowpermeability homogeneous and saturated media at small scale, to identify key parameters controlling the transport process. Sodium chloride $(\mathrm{NaCl})$ was chosen to be the tracer. A number of tracer tests were conducted to inspect the transport process under different conditions. The observed velocity-time behavior for different columns indicated the decline of soil permeability when switching from tracer introducing to tracer flushing. The modeling approaches considered were the Advection-Dispersion Equation (ADE), Two-Region Model (TRM), Continuous Time Random Walk (CTRW), and Fractional Advection-Dispersion Equation (FADE). It was found that all the models can fit the transport process very well; however, ADE and TRM were somewhat unable to characterize the transport behavior in leaching. The CTRW and FADE models were better in capturing the full evaluation of tracer-breakthrough curve and late-time tailing in leaching.
\end{abstract}

\section{Introduction}

Low-permeability porous media (LPPM) exist extensively in natural sedimentary deposits such as shale and clay. They have played critical roles in protecting groundwater resources, affecting the accumulation of petroleum and ore deposits, and controlling geological processes such as structural evolution of the crust [1-5]. Contaminant migration in clay-rich soils may still be important because in several areas these soils are placed on top of aquifers and along the streams. It is a little hard to understand the solute transport mechanism in LPPM using actual experiments. This is partially due to the challenges of designing adequate experimental apparatus for acquiring accurate data of flow and transport in such media, and partially due to the extremely long time needed for carrying out such experiments. For example, Gerke and Köhne [6] carried out bromide tracer tests and analyzed the preferential flow and bromide leaching with the dual-permeability method. Gongsheng et al. [7] considered an actual column test experiment with subclay soils and addressed the issues of inverse problems of parameter identification. Konikow et al. [8] presented the column experiments to address the so-called clay dispersion issue by quantifying the relations between permeability changes and clay mineralogy, clay content, and initial water salinity.

A large body of literature related to solute transport in LPPM often involved the so-called "numerical experiments" or numerical simulations where an imaginary rather than an actual experiment was conducted. For example, Guimerà and Carrera [9] interpreted the tracer test in low-permeability fractured media. Guswa and Freyberg [10] discussed a Peclet number that effectively characterized highly asymmetric solute transport breakthrough curves (BTCs) within lowpermeability enclosures. In Ozturk and Ozkan [11] the preferential flow phenomena were presented and insights were provided on the leaching process of salt through large clay loam and sandy clay loam soil columns. Hsieh and Freckleton [12] developed a MODFLOW module to efficiently simulate 
the three-dimensional solute transport in thin, vertical, lowpermeability geological media [13], while Chapman et al. [14] explored the validity of numerical models (e.g., HydroGeoSphere, FEFLOW, and MODFLOW/MT3DMS) in high resolution models to simulate diffusion into and out of lowpermeability regions. Chambon et al. [15] compared the Discrete Fracture Network (DFN) and Equivalent Porous Media (EPM) models, in terms of peak concentration and leaching time for contaminated sites in low-permeability fractured media. Li et al. [16] proposed a coupled solute transport model to assess the complicated interaction of the multifields and their impact on pollutant leakage through landfill liners. Leij and Bradford [17] presented an analytical solution for reactive transport in a dual-permeability medium with reversible and irreversible mass transfer between the aqueous and the sorbed phases. Barns et al. [18] applied HydroGeoSphere (HGS) to explain small scale tracer tests in a lowpermeability layer, where BTCs were characterized by the early-time slightly higher concentrations and the features of flow patterns were equated with the transport behavior of an inorganic conservative tracer.

Despite the above-mentioned investigations, solute transport in LPPM is still poorly understood in a general sense. For example, it is still unclear what governing equation to use for properly describing the transport process in such media and whether one can use the Fick's law to describe the transport process or not. Furthermore, if Fick's law can be used, what is the proper range of dispersivity values for LPPM, and how different are they from those for permeable sandy aquifers? One can only answer these questions by conducting the laboratory and/or field transport experiments in such media. Performance and analysis of controlled experiments in the laboratory permit the investigation of various flow phenomena and their parameters on relatively small scales of distance and time [19].

Tracer tests have been commonly used for several decades as benchmark experiments for investigating solute transport in porous media. A main contribution of this study that is different from previous tracer tests is to characterize transport in subsurface low-permeability media and the validity of the transport theories at various scales in such media. Ballard et al. [20] have taken into account radioactive tracers test to investigate the movement of water and stated that, under conditions of zero applied pressure, concentration gradients are the driving mechanism for mass transfer of ionic species through the shales. Solute transport in porous media was usually described by the Advection-Dispersion Equation (ADE) [21, 22]. According to Margolin and Berkowitz [23], $\mathrm{ADE}$ models are based on the assumption that dispersion behaves macroscopically as a Fickian process [24] with the dispersivity being assumed to be constant in space and time. However, sometimes dispersivity exhibits a scale-dependent feature [25] and $\mathrm{ADE}$ is not able to define such solute transport process effectively. Many researchers (e.g., [26-30]) showed that the measured concentrations were sometimes higher at the early arrival of breakthrough curves and lower at the tails of breakthrough curve than those estimated by ADE. Desbarats [31] reported a series of numerical tracer tests and found that the longitudinal macrodispersive spreading of a form is inconsistent with ADE. In these circumstances, the dispersion of solute transport with respect to time and distances was no longer behaving as a Gaussian form.

Cumbie and McKay [32] presented the influence of particle size on transport in a fractured clay-rich saprolite and investigated faster diffusion process on colloid distribution. As pointed out by Bromly and Hinz [33], non-Fickian transport behavior can also be recognized in homogeneous media. Alternatively, scientists have focused on employing new theories and techniques to study the observed solute transport behavior in the porous media. Pertinent among them is the Two-Region Model (TRM) offered by van Genuchten and Wierenga [34] to consider the nonequilibrium mass transfer process between the mobile and immobile zones in heterogeneous soils. Moreover, it has been established by several researchers that TRM can successfully simulate the transport behavior in homogeneous soils [35-37]. Both ADE and TRM are less satisfactory in describing certain tracer transport features, particularly in the case of late-time tailing and decrease in tracer concentration.

The discharge from low-permeability area in the groundwater can be considered a durable source that often challenges remediation strategies [38]. As reported by Cortis and Berkowitz [39], it is important to precisely determine both the early arrival and late-time tailing behavior for subsurface contaminants and for ground water remediation problems. Benson et al. [40, 41] presented the Lévy motion-based theory, namely, Fractional Advection-Dispersion Equation (FADE), to define and model these anomalous transports, and spatial and temporal spreading of solute concentration. FADE is successful in modeling saturated and unsaturated transport in porous media $[29,42-45]$ and is very useful for solute transport in soils for the separation of scale effects from the values of dispersion coefficient. Over the years, Continuous Time Random Walk (CTRW) has been applied to model a wide range of solute transport problems [46-48] including both laboratory $[39,49-51]$ and field tracer tests [52, 53].

On the other hand, Huang et al. [27] reported the contaminant transport analysis in homogeneous porous media, and Xiong et al. [28] modeled the solute transport in onedimensional homogeneous soil columns with ADE, CTRW, and FADE. Gao et al. [54] thoroughly evaluated the applicability of ADE, TRM, CTRW, and FADE in fitting and predicting BTCs for simulating anomalous tracer transport in a $12.5 \mathrm{~m}$ long heterogeneous soil column. Kuntz et al. [30] measured BTCs with ADE, TRM, and CTRW by performing tracer experiments to interpret solute transport behavior within bedrock.

The objective of this study is to report a series of carefully designed tracer test results of low-permeability clay soil columns. Three set of experiments were conducted: (i) same column diameter $(14 \mathrm{~cm})$ with different sample lengths $(3 \mathrm{~cm}$, $5 \mathrm{~cm}$, and $8 \mathrm{~cm}$ ); (ii) same sample length $(5 \mathrm{~cm})$ with different column diameters $(7 \mathrm{~cm}, 9 \mathrm{~cm}$, and $10 \mathrm{~cm})$; (iii) columns with rough inner wall, having the same diameter $(14 \mathrm{~cm})$ with different sample lengths $(3 \mathrm{~cm}, 5 \mathrm{~cm}$, and $8 \mathrm{~cm})$. Four different models including ADE, FADE, TRM, and CTRW were used to simulate the experimental results, and the transport behavior in LPPM was thorough analyzed. 
TABLE 1: Summary of soils sample diameters and particle size distribution (\%).

\begin{tabular}{ccccccc}
\hline$>0.075 \mathrm{~mm}$ & $0.075 \mathrm{~mm} \sim 0.05 \mathrm{~mm}$ & $0.05 \mathrm{~mm} \sim 0.01 \mathrm{~mm}$ & $0.01 \mathrm{~mm} \sim 0.005 \mathrm{~mm}$ & $0.005 \mathrm{~mm} \sim 0.002 \mathrm{~mm}$ & $<0.002 \mathrm{~mm}$ & Soil sample name \\
\hline $6.1 \%$ & $5.9 \%$ & $20.1 \%$ & $17.8 \%$ & $0.6 \%$ & $49.5 \%$ & Heavy silty clay \\
\hline
\end{tabular}

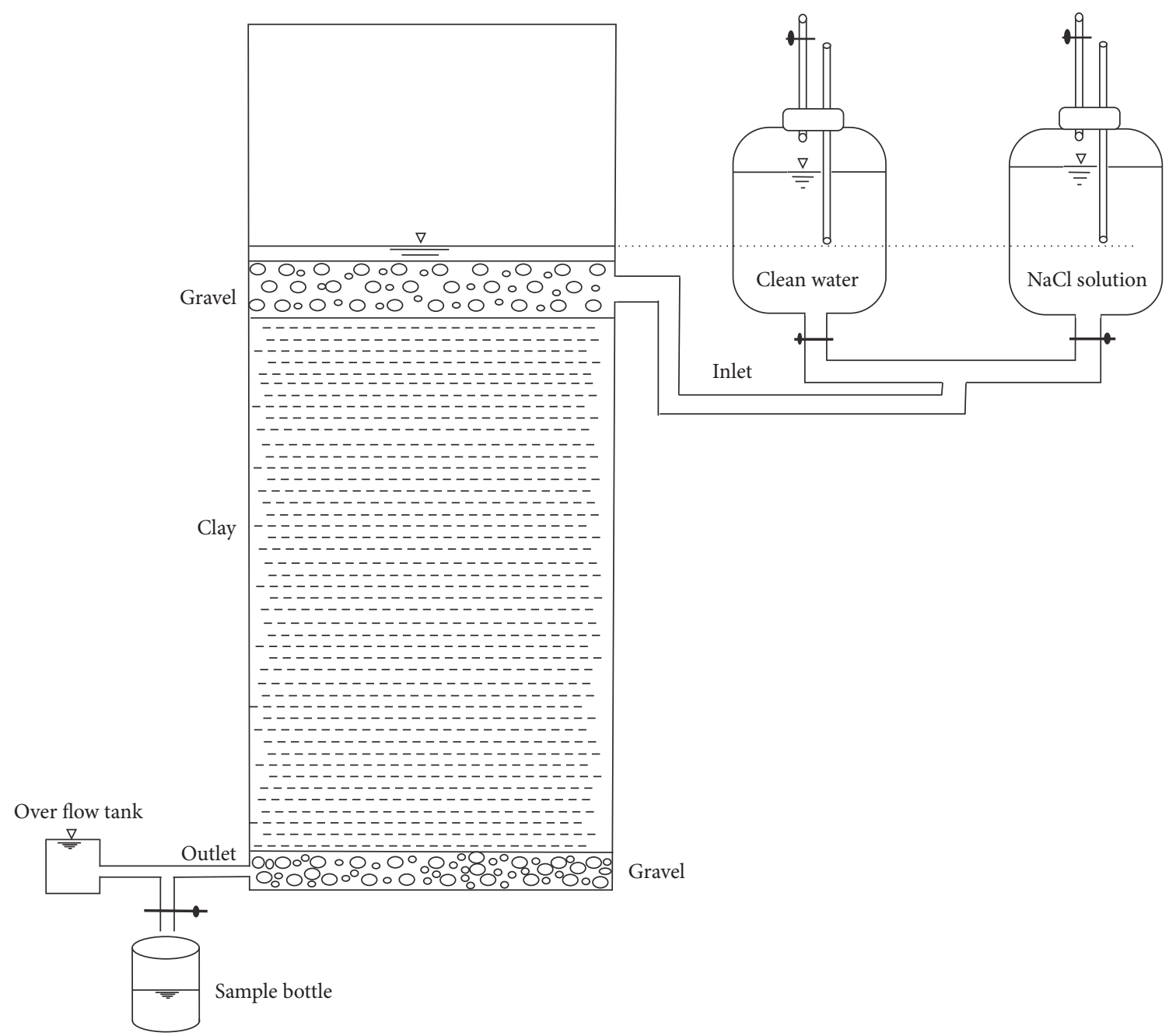

FIGURE 1: Schematic diagram for homogeneous and saturated columns experiments.

\section{Methods}

2.1. Column Experiments Preparation. We have conducted a series of laboratory experiments for one-dimensional solute transport in low-permeability homogeneous and saturated soil columns using vertical Plexiglas columns with various sample diameters of $7-14 \mathrm{~cm}$ and various sample lengths of $3-8 \mathrm{~cm}$. The homogeneous columns were filled with clay soil samples, which were taken from the nearby mountains in Wuhan, Hubei Province, China. For the clay media (i.e., Heavy silty- clay) used in this study hydraulic conductivity was found to be around $10^{-5} \mathrm{~cm} \mathrm{~s}^{-1}$ [55]. Approximately, similar hydraulic conductivity was reported by Neuzil [19] for clay soil. After the removal of all impurities such as gravel particles, residual leaves, and roots, then the clay particles with grain sizes smaller than $0.3 \mathrm{~mm}$ were used as testing media. The collected soil samples were air-dried, sieved, and stored at room temperature foregoing the experiments. Particle size distribution of soils used in the study is shown in Table 1, which is according to the People's Republic of China national standards GB/T50123-1999 "Earthwork Experimental Technique Standard." The bulk density and the total porosity of the soil columns are shown in Table 2.

2.2. Experimental Set-Up. The test installation comprised primarily of a water-supply device (Mabottle), a Plexiglas column, and a water outflow installment (steady-flow water tank); schematic diagram for the experiments is shown in Figure 1. Three sets of soil columns were prepared to observe the ground water flow and solute transport characteristics due to the change in soil column length and diameter: (i) same column diameter $(14 \mathrm{~cm})$ with different column lengths 


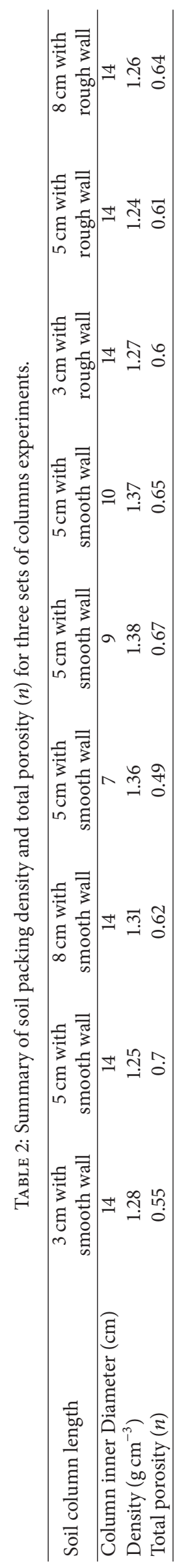


$(3 \mathrm{~cm}, 5 \mathrm{~cm}$, and $8 \mathrm{~cm})$; (ii) same column length $(5 \mathrm{~cm})$ with different column diameters $(7 \mathrm{~cm}, 9 \mathrm{~cm}$, and $10 \mathrm{~cm})$; (iii) columns with rough inner wall, having the same diameter $(14 \mathrm{~cm})$ with different column lengths $(3 \mathrm{~cm}, 5 \mathrm{~cm}$, and $8 \mathrm{~cm})$. For above sets of (i) and (ii) the inner walls of the soil columns are smooth. The inner wall of the soil column in set (iii) is rough and the roughness is somewhat similar to the grain size of the sample. The entrance and exit surfaces of packed soil columns were covered with gravels with particle diameters of $2 \sim 3 \mathrm{~cm}$.

The column was then filled from bottom with tap water for 48-72 hours to make the soil fully saturated. During water saturation process, if the bubbles or cracks appeared within the soil columns, the soils were extracted from the columns then refilled and saturated again from the bottom to ensure that no bubbles or cracks can be found and the soils were as homogeneous as possible. After establishing steady-state saturated flow through the column, two conjugate tracer tests were carried out with each of three sets of soil columns.

During the experiments, the temperature in the laboratory was around $25^{\circ} \mathrm{C}$, meaning that the viscosity of the water can be regarded as constant. The electrical conductivity of the water samples from the tap was measured using a portable conductivity meter DDBJ-350 which has a precision of $\pm 1.0 \%$. The first test was a tracer introducing test with a constant $\mathrm{NaCl}$ source concentration of $5 \mathrm{~g} \mathrm{~L}^{-1}$ (or $0.085 \mathrm{~mol} \mathrm{~L}^{-1}$ ) and the subsequent second test was a flushing (or leaching) test after the exit tracer concentration became stable. A tracer injection experiment in the homogeneous clay soil column was done by replacing inflowing tap water with a $\mathrm{NaCl}$ concentration $(5 \mathrm{~g} / \mathrm{L})$ and in leaching experiment the initial concentration $(5 \mathrm{~g} / \mathrm{L})$ was replaced with the tap water. The concentration used in the experiment may be higher than values used in some other experiments but this value should not affect the conclusion of this study as we were dealing with the relative concentration (i.e., the ratio of actual concentration over the constant source concentration). One benefit of using a higher concentration was for the easy measurement and likely reduction of relative measurement errors. $\mathrm{NaCl}$ is favorable to estimate ground water flow and transport properties, and is also environmentally benign. Similarly high values of $\mathrm{NaCl}$ [56] were used by Inoue et al. [57] which presented the results of soil hydraulic and solute transport parameters with different $\mathrm{NaCl}$ concentrations (e.g., $0.04,0.05,0.06,0.08,0.1,0.2,0.5$, and $1.0 \mathrm{~mol} / \mathrm{L}$ ). The head difference over the sample was set around $43 \mathrm{~cm}$ to ensure that the hydraulic gradient was much greater than the threshold hydraulic gradient.

\section{Results and Discussion}

3.1. Characteristics of the Flow Velocities. The Darcian velocity is an essential element in solute transport and is calculated from the following [58]:

$$
q=\frac{Q}{A}
$$

where $q$ is the Darcian velocity $\left(L T^{-1}\right), Q$ is the total discharge $\left(L^{3} T^{-1}\right)$ which can be measured during the experiments, and $A$ is the inner cross-sectional area $\left(L^{2}\right)$ of the column.

In three sets of experiments, Darcian velocity was found to decrease with time, as shown in Figures 2(a), 2(b), and 2(c). Three distinctive stages were observed in such a velocity-time profile for each experimental set-up. The first stage (A) was a tracer introducing period. The second stage (B) was a flushing period, which also showed a sharp decline in Darcian velocity, suggesting the decline of soil permeability. In other words, the soil samples during the flushing period were not the same as those for the tracer introducing period, although one did not change the actual soils in the column. This implied that at least for tracer tests in LPPM, the transport processes for the tracer introducing test and tracer flushing test could be different because the properties of the soil had been inevitably altered during the switch from tracer introduction to tracer flushing. The third stage $(\mathrm{C})$ was a stabilized Darcian velocity after sufficiently long time of flushing, indicating that the permeability of the soil reached a new stable stage again. The decline of Darcian velocity might be due to the clay dispersion and swelling in the saline water, as also pointed in some previous studies [59-61]. Konikow et al. [8] provided a nice discussion on the relationship of permeability change and clay mineralogy, clay content, and initial water salinity.

In the first set-up of our experiment (case (i)), the same diameter $(14 \mathrm{~cm})$ with different column lengths $(3 \mathrm{~cm}$, $5 \mathrm{~cm}$, and $8 \mathrm{~cm}$ ) was applied. The Darcian velocities $(q)$ for the tracer introducing period in $3 \mathrm{~cm}, 5 \mathrm{~cm}$, and $8 \mathrm{~cm}$ soil columns were stable around $0.25 \mathrm{~cm} \mathrm{~h}^{-1}, 0.15 \mathrm{~cm} \mathrm{~h}^{-1}$, and $0.02 \mathrm{~cm} \mathrm{~h}^{-1}$, respectively, as shown in Figure 2(a). During the leaching process, the Darcian velocities in $3 \mathrm{~cm}$ and $5 \mathrm{~cm}$ columns were approximately the same which was around $0.05 \mathrm{~cm} \mathrm{~h}^{-1}$. It was found that Darcian velocity in the $8 \mathrm{~cm}$ column was less than that in the $3 \mathrm{~cm}$ and $5 \mathrm{~cm}$ columns and was relatively stable; that is, it remained nearly the same at the tracer introducing and flushing periods (Figure 2(a)). This result suggested that permeability of the $8 \mathrm{~cm}$ column was not obviously altered during the tracer introducing and flushing periods, not as those observed for the $3 \mathrm{~cm}$ and $5 \mathrm{~cm}$ columns. This implied that the so-called clay dispersion and swelling effect was less in the $8 \mathrm{~cm}$ column than that in the $3 \mathrm{~cm}$ and $5 \mathrm{~cm}$ columns.

Figure 2(b) showed the Darcian velocity for case (ii) and differences were clearly observed in all three columns. Furthermore, it also showed that the tracer introducing and flushing Darcian velocities were reduced compared to their counterparts in the first set of experiments (Figure 2(a)). It was also found that the smaller the diameter of soil column, the slower the Darcian velocity. This may be understood as follows. For a cylindrical column with an inner radius of $R$ (or an inner diameter of $2 R$ ) and length of $L$, the wall surface/volume ratio is $2 \pi R L / \pi R^{2} L=2 / R$. Therefore, a smaller inner diameter of soil column will lead to a greater wall surface/volume ratio, thus a relatively greater wall surface resistance to flow, and eventually a smaller Darcian velocity. A significant difference was found in Figures 2(a) and 2(b), indicating that the bulk permeability of the soil columns could be very different when the same clay 


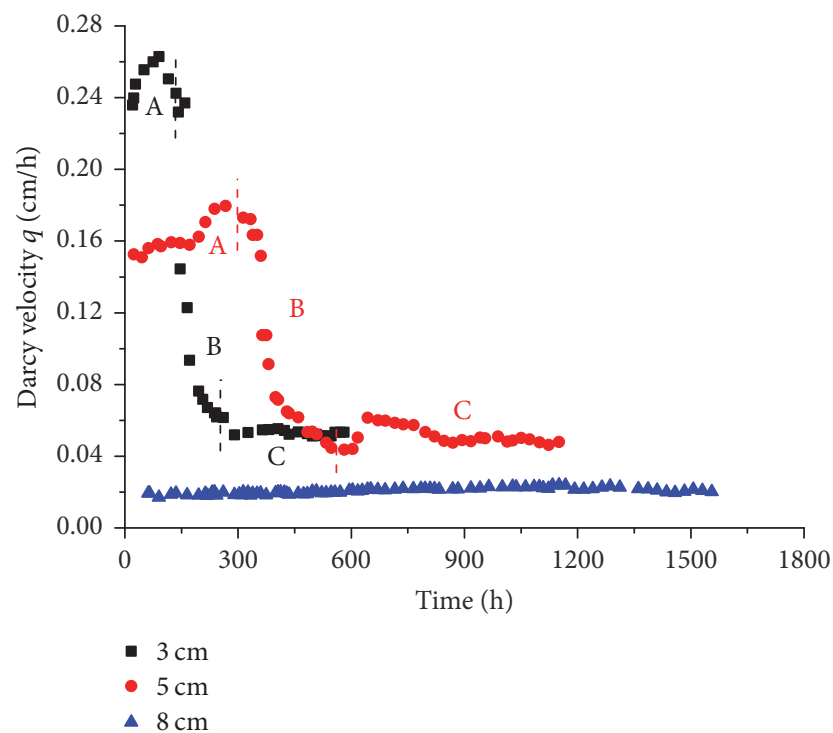

(a)

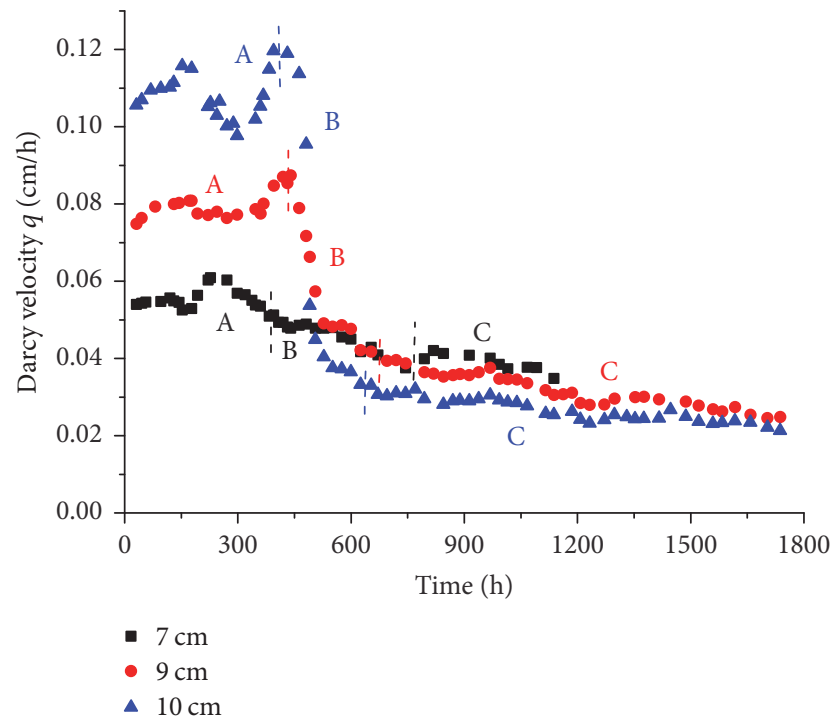

(b)

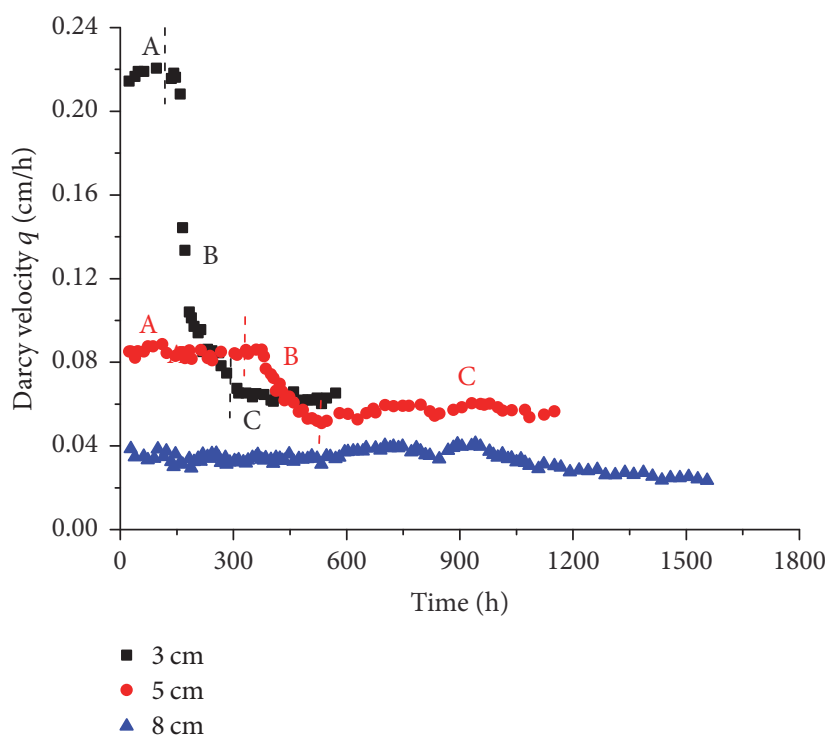

(c)

FIGURE 2: Darcian velocity versus time for three column experiments: (a) smooth wall soil columns with the same inner diameter (14 cm) but different lengths; (b) smooth wall soil columns with the same column length $(5 \mathrm{~cm})$ but different column inner diameters; (c) rough wall soil columns with the same inner diameter $(14 \mathrm{~cm})$ but different column lengths.

materials were packed into columns with different diameters and lengths.

At the tracer introducing period in Figure 2(c) for case (iii) (the rough wall columns), Darcian velocities were slower than their counterparts of the smooth wall columns in Figure 2(a). It is interesting to see that the Darcian velocities in both the $8 \mathrm{~cm}$ smooth wall (Figure 2(a)) and rough wall (Figure 2(c)) columns were relatively stable; that is, they are nearly independent of time at both the tracer introducing and flushing periods.

3.2. Simulation Results of BTCs. The mathematical and numerical simulation methods for ADE, FADE, TRM, and
CTRW were provided in Supplementary Material available online at https://doi.org/10.1155/2017/6390607.

Figures 3(a), 3(b), and 3(c) showed the observed and fitted BTCs of the smooth wall columns with lengths of $3 \mathrm{~cm}, 5 \mathrm{~cm}$, $8 \mathrm{~cm}$ and a diameter of $14 \mathrm{~cm}$, Figures 4(a), 4(b), and 4(c) showed the results of $5 \mathrm{~cm}$ column with diameters of $7 \mathrm{~cm}$, $9 \mathrm{~cm}$, and $10 \mathrm{~cm}$, and Figures 5(a), 5(b), and 5(c) showed the results for the rough wall columns with lengths of $3 \mathrm{~cm}$, $5 \mathrm{~cm}$, and $8 \mathrm{~cm}$, all with a diameter of $14 \mathrm{~cm}$. The BTCs at each soil column length and diameter were individually fitted with ADE, FADE, TRM, and CTRW. The estimated parameters were shown in Table 3. As shown in Figures 3-5, the experimental data can be well fitted by all these four 


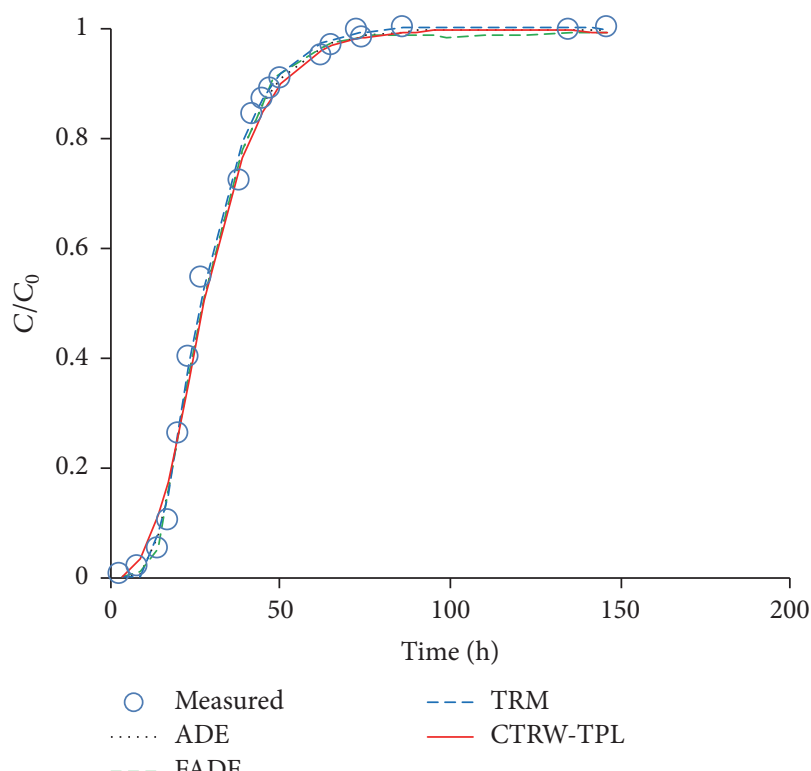

(a)

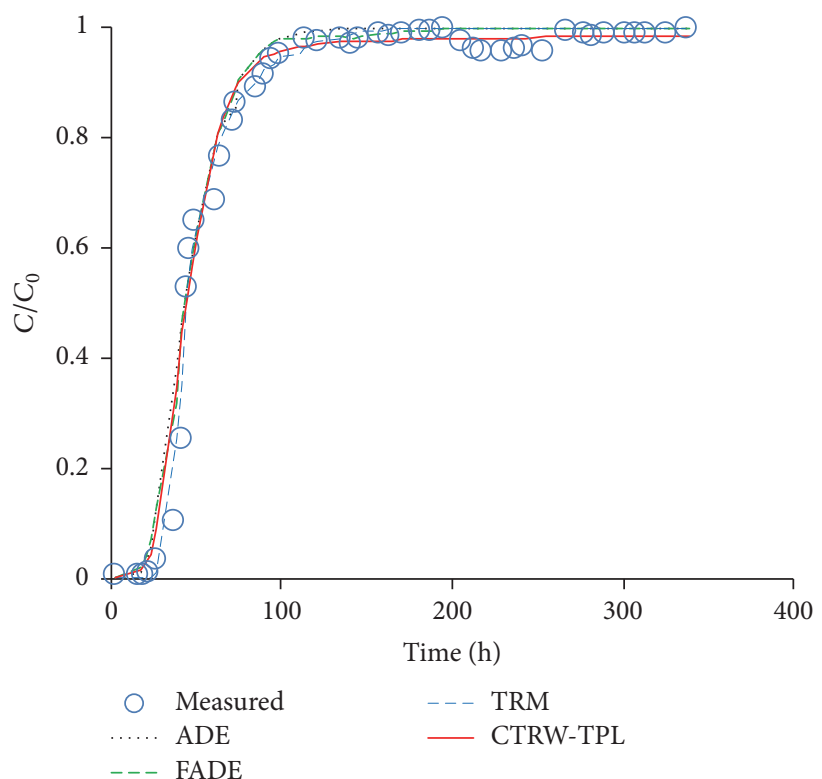

(b)

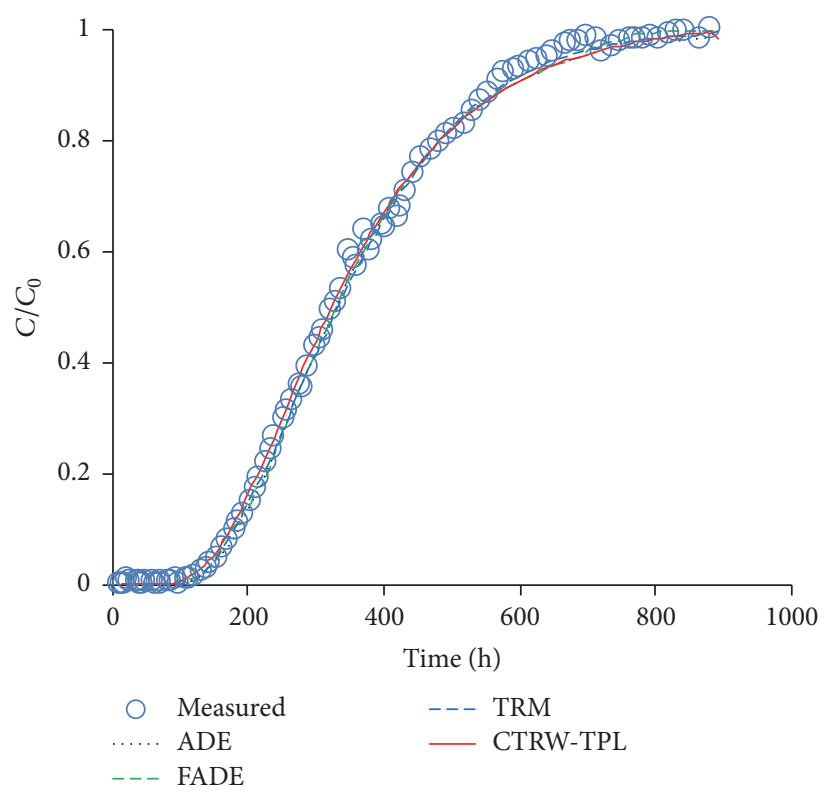

(c)

FIgURE 3: Three sets of measured breakthrough curves fitted with ADE, FADETRM, and CTRW (based on TPL), for the homogeneous, saturated, and smooth wall soil columns with the same inner diameter $(14 \mathrm{~cm})$ but different column lengths: (a) $3 \mathrm{~cm}$; (b) $5 \mathrm{~cm}$; (c) $8 \mathrm{~cm}$.

models with corresponding $R^{2}$ values all over 0.98 and the small values of the RMSE (see Table S1 in Supplementary Material).

The values of dispersivity $(\alpha)$ in the ADE model as shown in Table 2 are defined as $\alpha=D / v$ when neglecting the molecular diffusion term. It is worth pointing out that all the columns used in the experiments were packed and saturated using the same method with the same clay materials. Therefore, those columns should have similar values of physical properties such as permeability, porosity, and dispersivity. However, the values of dispersivity $(\alpha)$ in the ADE model as shown in Table 3 clearly indicated an increasing trend with column length. Such a trend was most likely a scaledependent effect, rather than an artifact of sample preparation.

It was found that the dispersion coefficient $(D)$ fitted using ADE was less than that estimated using FADE, which was consistent with previous studies [27, 54]. Furthermore, the estimated $\lambda$ values (the order of fractional differentiation) in FADE were in the range of $1.81-1.99$, which was very close to 2.00 , a value representing Fickian transport. At the $3 \mathrm{~cm}$ and $5 \mathrm{~cm}$ columns, $D_{\psi}$ values (generalized dispersion coefficient) fitted using CTRW were around $0.094 \mathrm{~cm}^{2} \mathrm{~h}^{-1}$ and $0.101 \mathrm{~cm}^{2} \mathrm{~h}^{-1}$, respectively. The $D_{\psi}$ value in the $8 \mathrm{~cm}$ column 


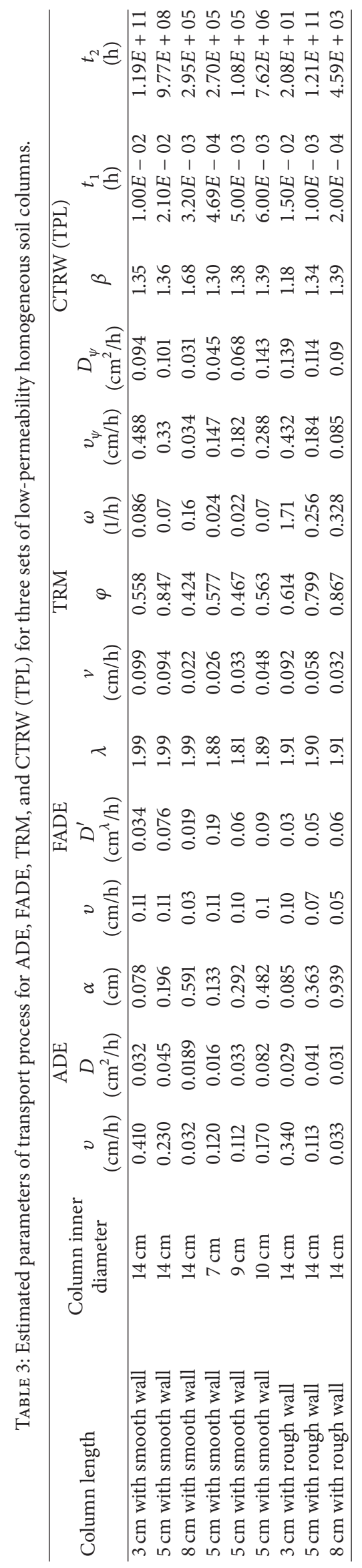




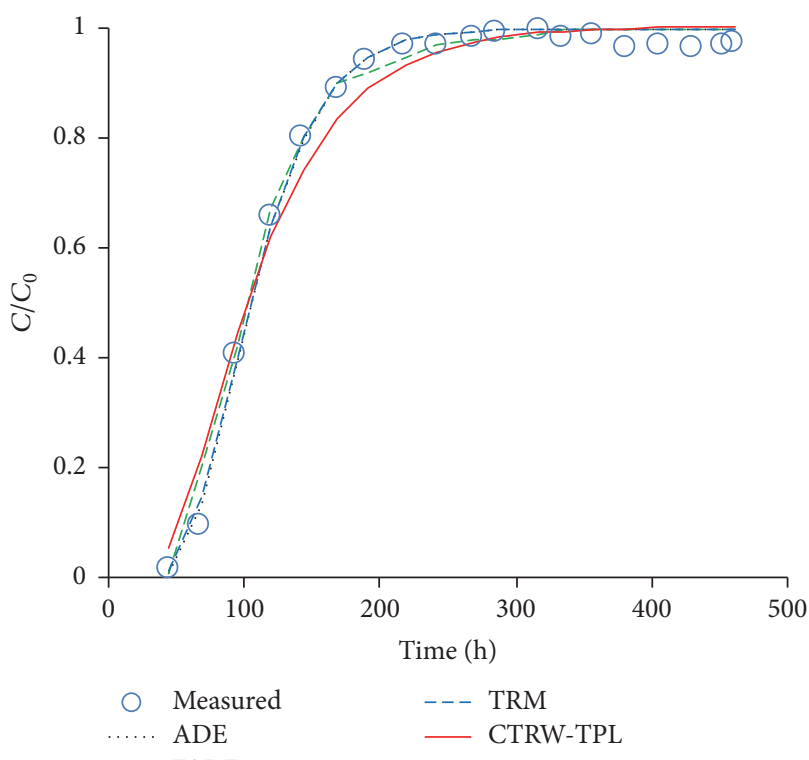

(a)

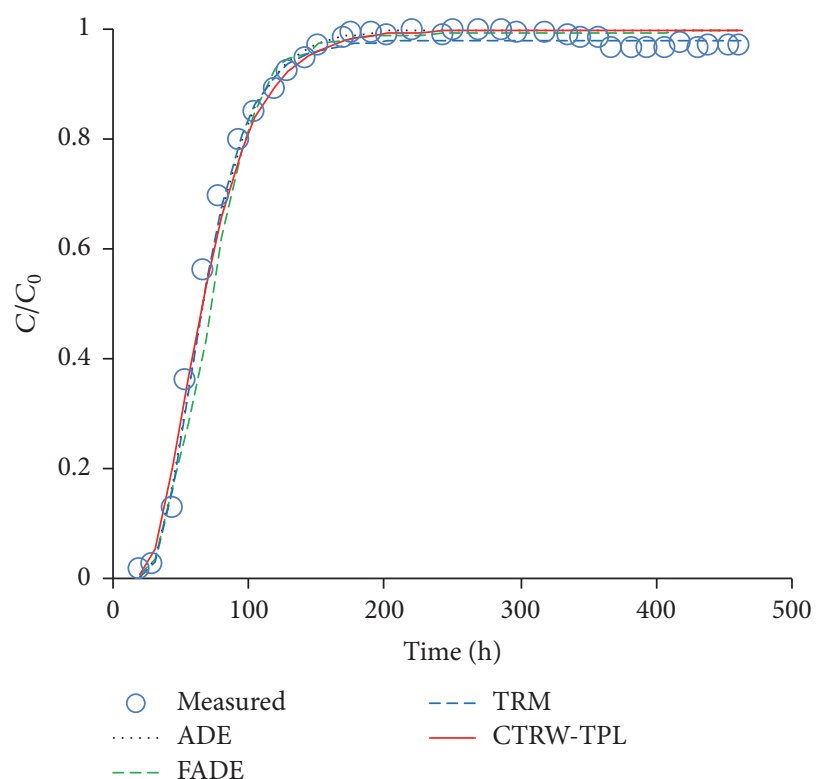

(b)

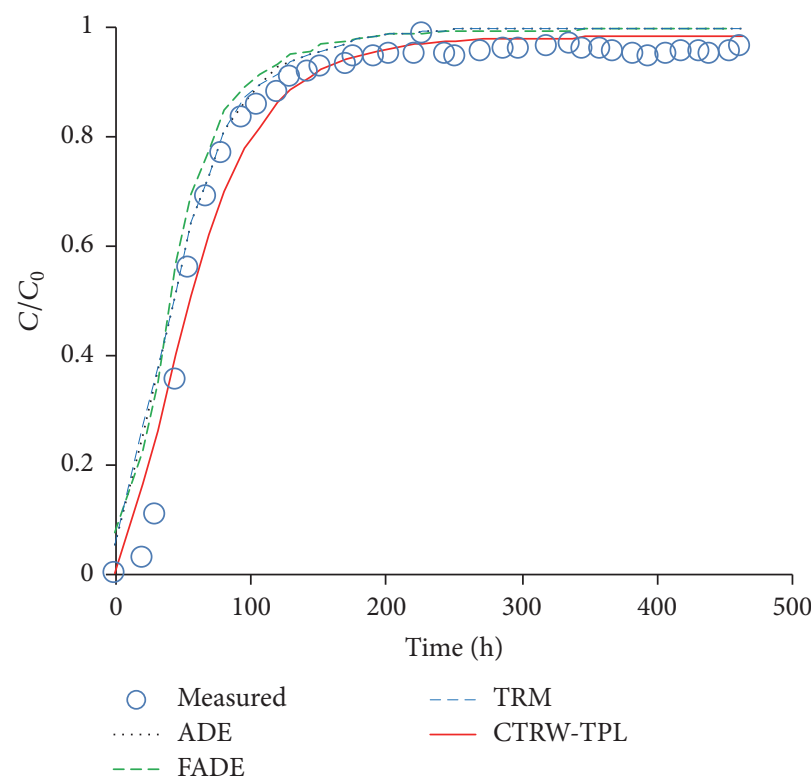

(c)

FIGURE 4: Three sets of measured breakthrough curves fitted with ADE, FADE, TRM, and CTRW (based on TPL), for the homogeneous, saturated, and smooth wall soil column with the same column lengths $(5 \mathrm{~cm})$ but different column inner diameters: (a) $7 \mathrm{~cm}$; (b) $9 \mathrm{~cm}$; (c) $10 \mathrm{~cm}$.

was smaller than those at the $3 \mathrm{~cm}$ and $5 \mathrm{~cm}$ columns. This suggested that the CTRW theory used here may only account for stationary media and it did not reveal the multiple-scale heterogeneities with a single $D_{\psi}$ value [54]. The values of cut-off time $\left(t_{2}\right)$ for the truncated power-law transition-time distribution function were larger than $t_{1}$ (a characteristics time), indicating that transition to Fickian transport had not yet occurred. As a result, the transition-time distribution was primarily controlled by $\beta$ (a dispersion related dimensionless parameter). It was found that the $\beta$ values in the CTRW model followed an increasing pattern towards 2.00. This implied that the transport would eventually evolve into a Fickian form at a sufficiently long column length.

A slow rise of BTCs was observed in columns with diameters of $7 \mathrm{~cm}$ and $9 \mathrm{~cm}$ compared to the column with a diameter of $10 \mathrm{~cm}$ (Figure 4). However, Darcian velocities during the tracer introducing period in the $10 \mathrm{~cm}$ diameter soil column were higher than those in $7 \mathrm{~cm}$ and $9 \mathrm{~cm}$ diameter columns (see Figure 2). Lack of tailing was observed in BTCs near the inlet in the $10 \mathrm{~cm}$ diameter column. Immediate arrival of concentration was observed for the $10 \mathrm{~cm}$ diameter column compared to those for the $7 \mathrm{~cm}$ and $9 \mathrm{~cm}$ diameter 


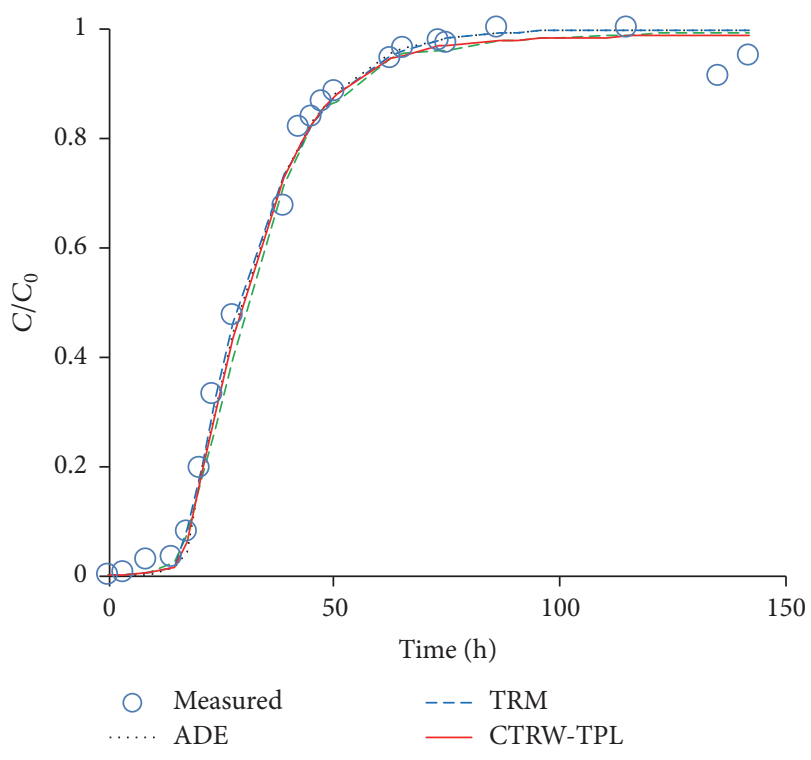

(a)

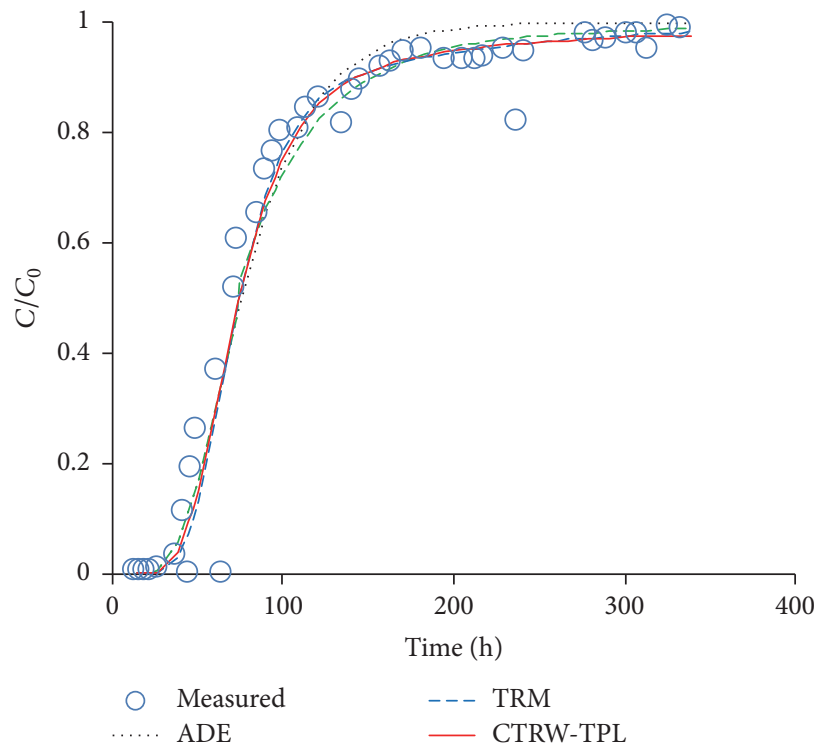

(b)

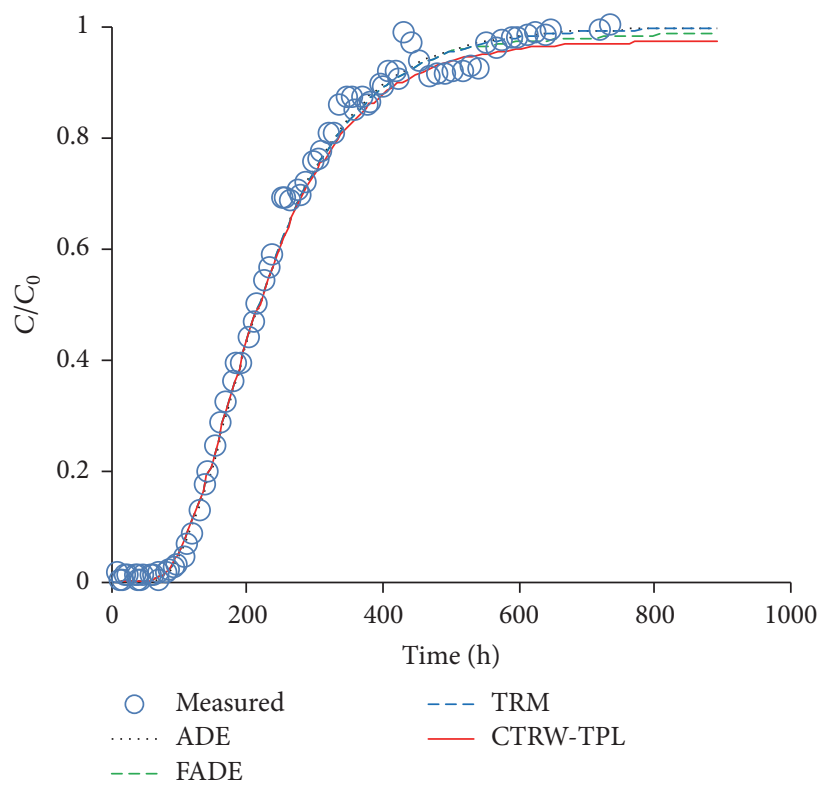

(c)

FIGURE 5: Three sets of measured breakthrough curves fitted with ADE, FADE, TRM, and CTRW (based on TPL), for the homogeneous, saturated, and rough wall soil columns with the same inner column diameter $(14 \mathrm{~cm}$ ) but different column lengths: (a) $3 \mathrm{~cm}$; (b) $5 \mathrm{~cm}$; (c) $8 \mathrm{~cm}$.

columns. This implied that the advective solute transport through the preferential pathways was short, which was consistent with previous studies $[28,54]$. This also showed that as the tracer moved relatively faster, its residence time (RT) was smaller, and the transport was less Fickian. Similar transport behavior was also reported by Berkowitz and Scher [50].

As seen in Table 3, there was a significant relationship between the column diameter and the dispersivity $(\alpha)$ fitted using ADE. A larger column diameter (such as $10 \mathrm{~cm}$ ) tended to produce a greater dispersivity $(\alpha)$ than columns with diameters of $7 \mathrm{~cm}$ and $9 \mathrm{~cm}$. This was a reflection of the greater difficulty in uniformly packing a larger diameter column in which media heterogeneity was almost inevitable and would lead to greater (macro) dispersivity. The estimated values of dispersion coefficient $(D)$ of ADE were smaller than those of FADE, as evident in Table 3. This agreed with previous investigations of Huang et al. [27] and Gao et al. [54]. The order of frictional differentiation $(\lambda)$ value was within the range of 1.88-1.89 and very close to 2.00 , once again suggesting that breakthrough process at columns with different diameters was close to Fickian. The TRM estimated values of mass transfer coefficient $(\omega)$ decreased with column 


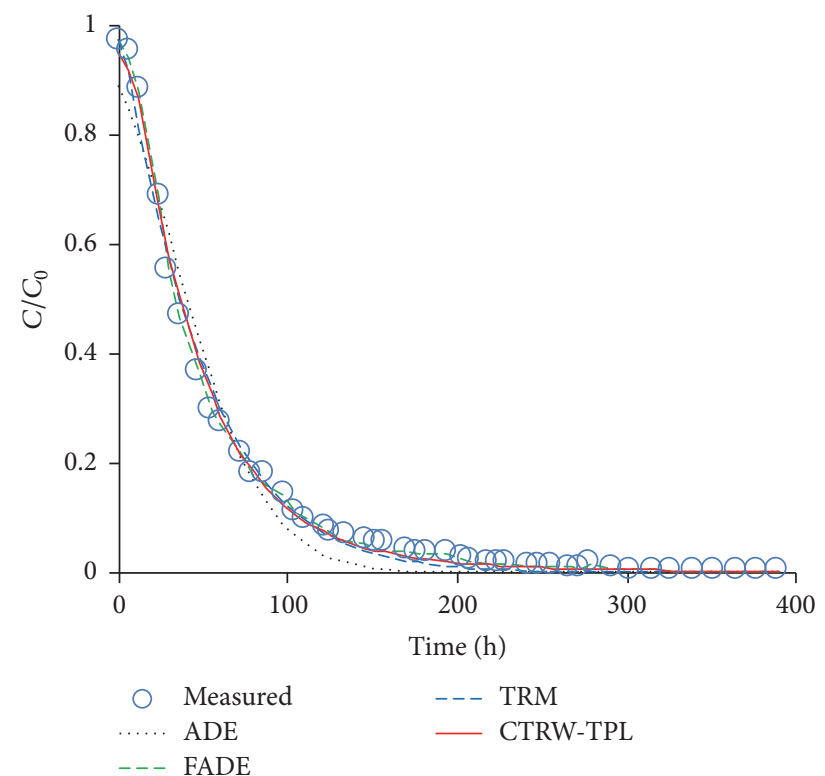

(a)

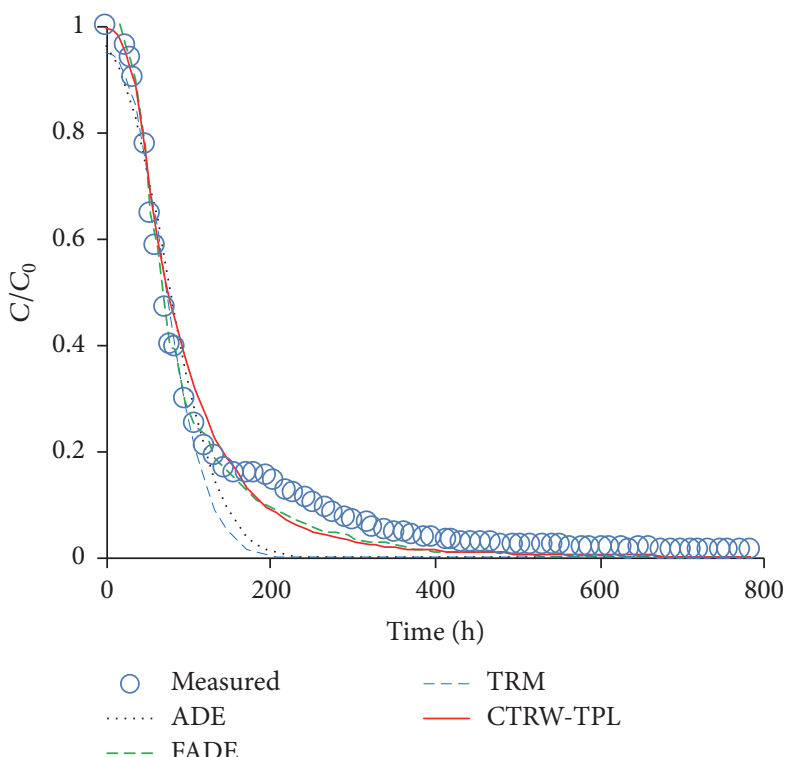

(b)

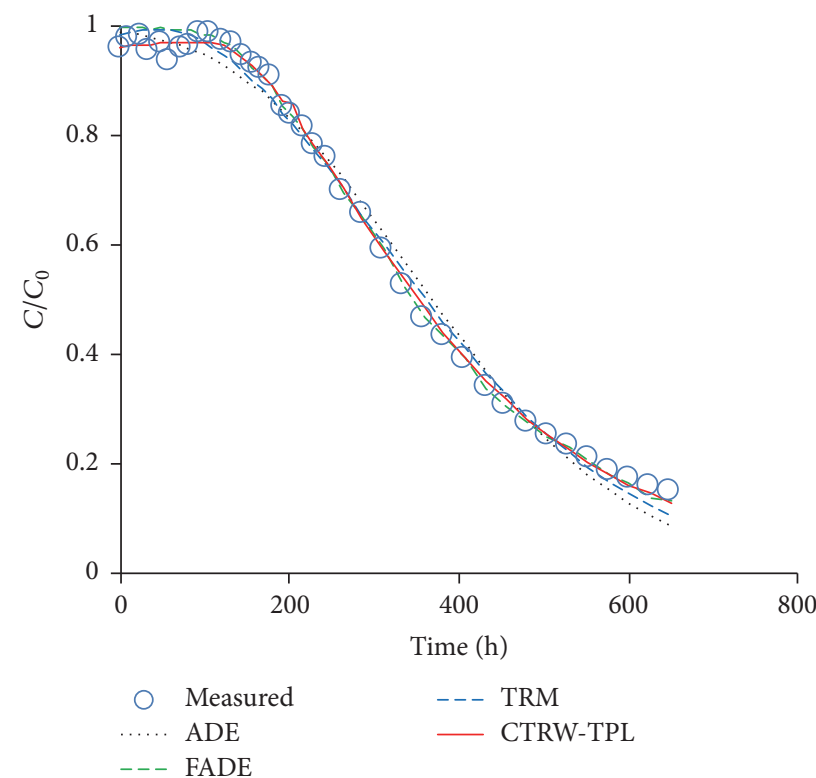

(c)

FIGURE 6: Three sets of measured leaching curves fitted with ADE, FADE, TRM, and CTRW (based on TPL), for the homogeneous, saturated, and smooth wall soil columns with the same inner diameter $(14 \mathrm{~cm}$ ) but different column lengths: (a) $3 \mathrm{~cm}$; (b) $5 \mathrm{~cm}$; (c) $8 \mathrm{~cm}$.

diameter, as shown in Table 3. This suggested a certain degree of correlation between advective residence time and mass transfer timescale $[62,63]$.

Figure 5 showed that the fitting results of all four models were consistent with the measured BTCs in the rough wall columns. The increasing trend of $\beta$ values towards 2.00 in the CTRW model for the rough wall column experiments was also a piece of evidence supporting the Fickian transport behavior during the breakthrough process [64].

3.3. Simulation Results of Leaching Curves. The leaching process (or solute flushing period) was well simulated with
CTRW and FADE in Figures 6-8. It was found that FADE performed the best for fitting the leaching data. Other than FADE, CTRW also performed very well with the leaching data. On the contrary, ADE and TRM did not capture the leaching process very well. Good performance of CTRW and FADE in Figures 6-8 was also reflected by the larger $R^{2}$ values and smaller RMSE values than their counterparts resulting from the ADE and TRM models (see Table S2 in Supplementary Material).

Figure 6 compared the observed and fitted leaching curves for the first set of column experiments (case (i)). The dispersivity $(\alpha)$ variation in Table 4 attributed such a 


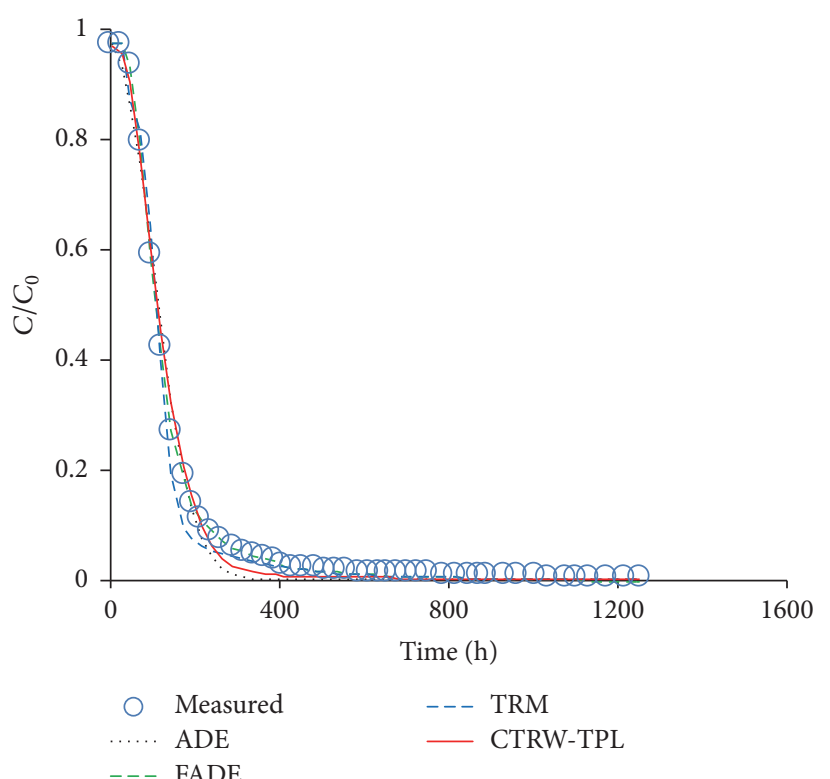

(a)

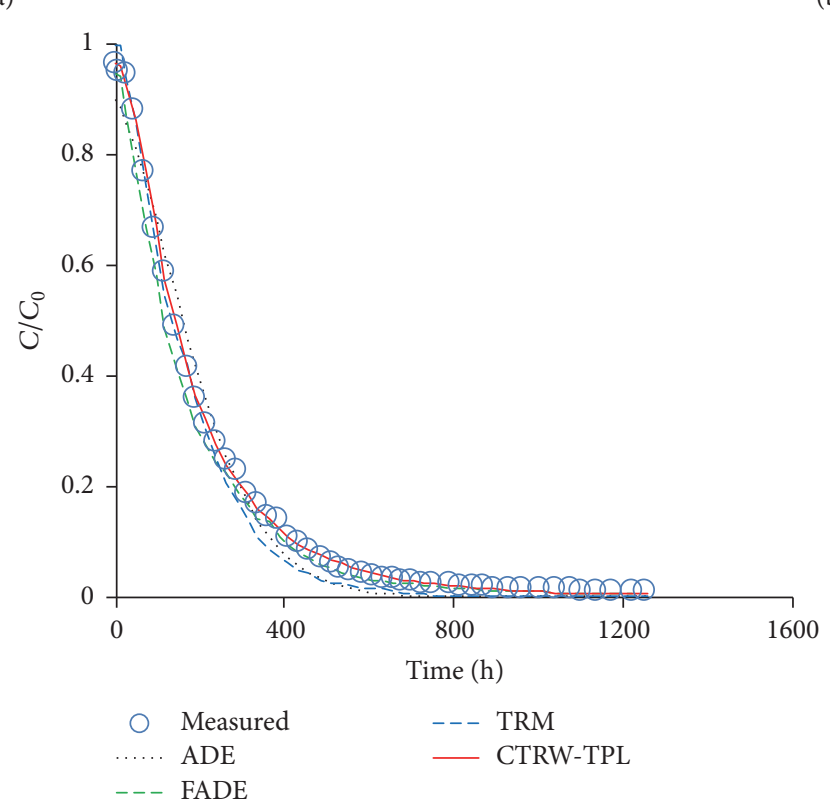

(c)

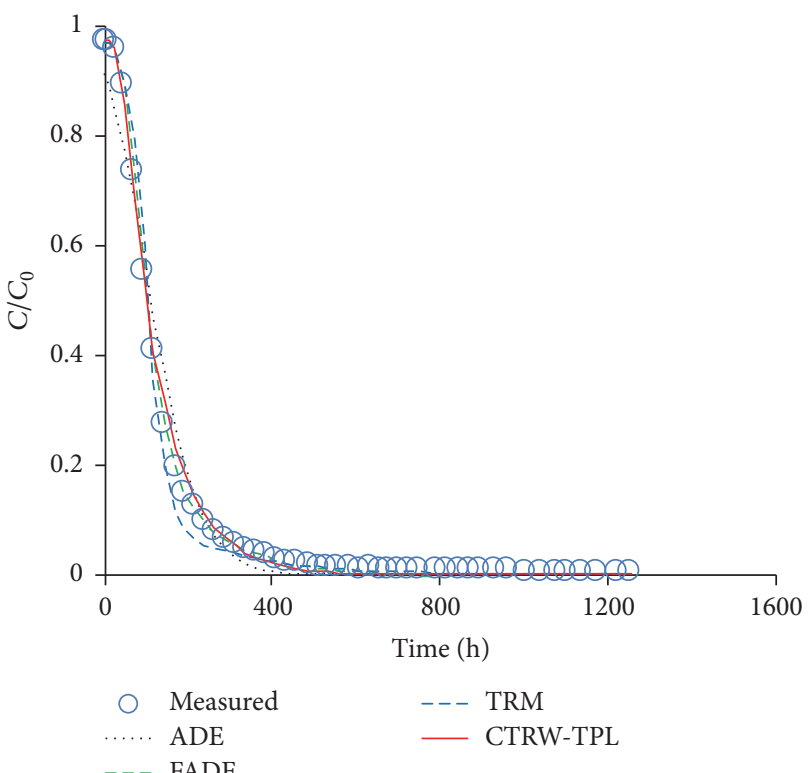

(b)

FIGURE 7: Three sets of measured leaching curves fitted with ADE, FADE, TRM, and CTRW (based on TPL), for the homogeneous, saturated, and smooth wall soil columns with the same column length $(5 \mathrm{~cm}$ ) but different column inner diameters: (a) $7 \mathrm{~cm}$; (b) $9 \mathrm{~cm}$; (c) $10 \mathrm{~cm}$.

discrepancy to the specific makeup of heterogeneities in the columns. The estimated $\lambda$ values for FADE were in the range of 1.7, which was considerably smaller than 2.00 (Table 4). The CTRW fitting velocity $\left(v_{\psi}\right)$ was smaller than the velocity values in ADE, TRM, and FADE, and $D_{\psi}$ values of CTRW increased with the column length. Similar results about $v_{\psi}$ and $D_{\psi}$ changes were examined by Berkowitz et al. [24] in short-column experiments. The $\beta$ values in the CTRW model were between 1.15 and 1.4. All these evidences showed that the FADE and CTRW fitting results were better in capturing the leaching process in Figure 5 than ADE and TRM. Similar conclusion can be drawn for the leaching processes in case (ii) (see Figure 7) and in case (iii) (see Figure 8).
A slight increase of measured concentration (bump) was found around $200 \mathrm{hr}$ in Figure 6(b) in case (i) and Figure 8(b) in case (iii). Actually, the bump in Figures 6(b) and 8(b) can be explained by checking the feature of the velocities. As shown in Figures 2(a) and 2(c), one can see that the velocity decreased around $300 \mathrm{hr}$ (this was the time leaching or flushing started) to $550 \mathrm{hr}$ (the time of the bump, around $200 \mathrm{hr}$ after flushing). Such a declining velocity feature cannot be easily incorporated into the analytical models employed in this study. However, one can reasonably speculate that decrease of flushing velocity will generally lead to decrease of flushing efficiency. In other words, the concentration may not drop as fast as the case when the flushing velocity remains 


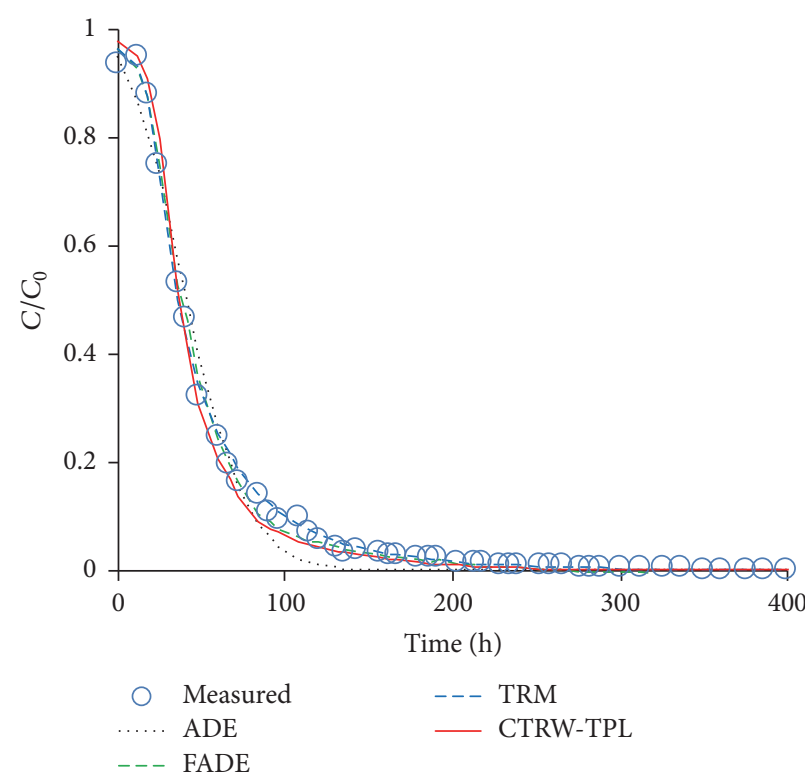

(a)

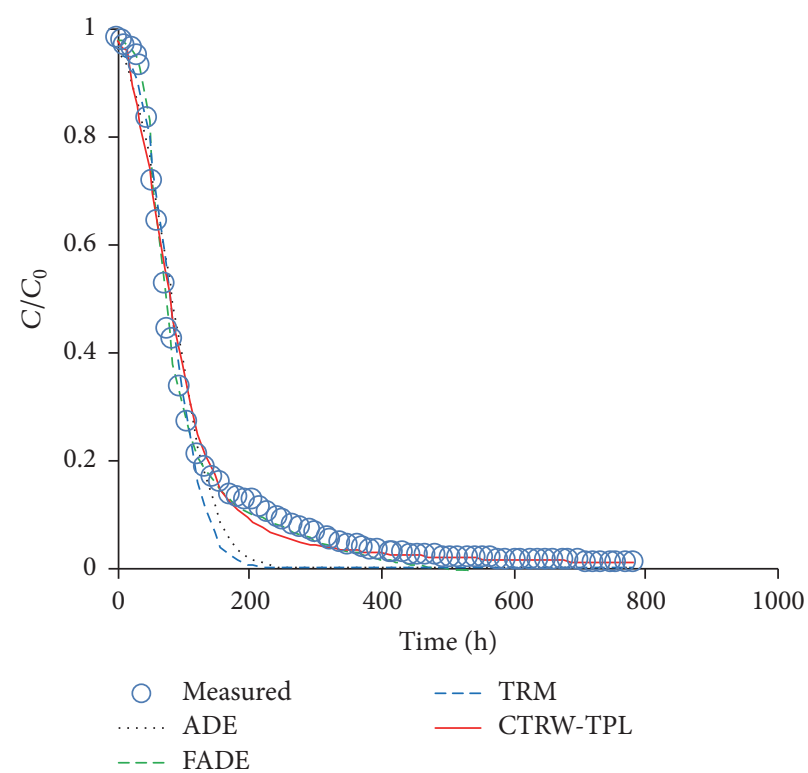

(b)

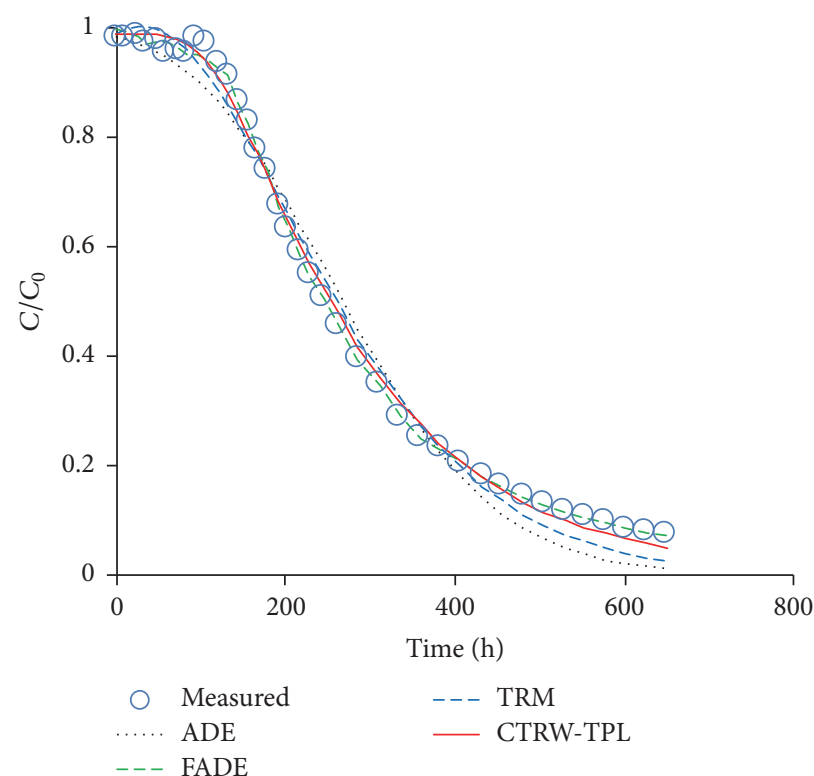

(c)

FIGURE 8: Three sets of measured leaching curves fitted with ADE, FADE, TRM, and CTRW (based on TPL) for the homogeneous, saturated, and rough wall soil columns with the same inner diameter $(14 \mathrm{~cm}$ ) but different lengths: (a) $3 \mathrm{~cm}$; (b) $5 \mathrm{~cm}$; (c) $8 \mathrm{~cm}$.

the same. This may qualitatively explain the slight increase of concentration (bump) observed in Figures 6(b) and 8(b). A high resolution numerical model that incorporates the entire velocity variation spectrum will be desirable to offer a better quantitative understanding of such a small anomaly during the flushing phase of the experiment. This is out of the scope of this study and will be pursued in a future investigation.

\section{Discussion}

The above experimental results indicate that the hydraulic conductivity value depends on the clay soil structure and it might also be changed by the contaminants in the leaching process. On the other hand, Darcian velocity tends to decrease with time because of the decline of soil permeability that may be caused by the clay dispersion and swelling in the saline water. The decline of Darcian velocity is also likely due to the column wall roughness.

An interesting finding for transport in clay media is that the leaching process is not a simple reversal of the breakthrough process, as often assumed for transport in sandy porous media before. Instead, the leaching process sometimes exhibits very different behavior from the breakthrough process, most likely due to the clay dispersion and 


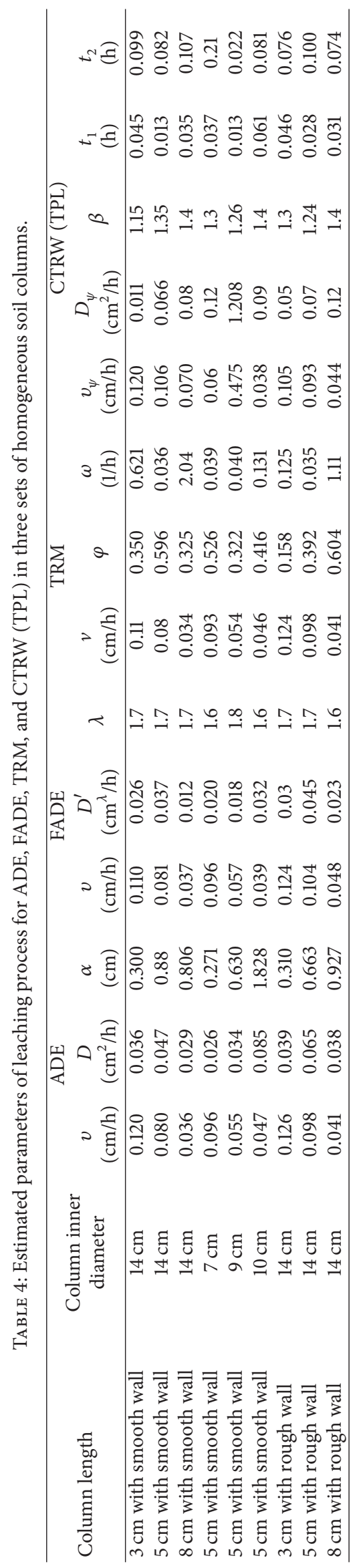


swelling problem. This implies that when studying transport in LPPM such as clay, it is advisable to investigate both the breakthrough and leaching processes, rather than the breakthrough process alone. Another interesting feature is that the dispersivity $(\alpha)$ for the leaching process (Table 4 ) is higher than that in the breakthrough process (Table 3 ), which indicates that the pore structure must be changed when switching from breakthrough process to leaching process, as $\alpha$ is closely related to the pore structure. This feature also indicates that the leaching process has a great capability towards the non-Fickian transport.

It is found that CTRW and FADE models can better describe the late-time tailing in the leaching process than ADE and TRM. Therefore, ADE and TRM are not recommended to explain the leaching process, although they are acceptable in describing the breakthrough process (Figures 3-5).

We have to point out that this study deals with relatively small scales of columns with lengths ranging from $3 \mathrm{~cm}$ to $8 \mathrm{~cm}$ and column diameters from $7 \mathrm{~cm}$ to $14 \mathrm{~cm}$. Actually, this study can be regarded as a pilot study and the first attempt of conducting transport experiments in LPPM to see how different transport in LPPM is from transport in other permeability media such as sand. Such a pilot study and experiment gained from this study will be very useful steps for more complete, full scale investigation of transport in LPPM, including conducting repetitive experiments. Therefore, whether the findings of this study can be extended to field scales or not is unknown and needs further investigations. Nevertheless, this study offers some interesting results about transport in clay, and, most importantly, it emphasizes the importance of analyzing both the breakthrough and leaching processes in clay.

\section{Conclusions}

The following conclusions can be drawn from this study:

(1) Three stages of Darcian velocity were found when switching from breakthrough process (or tracer introducing stage) to leaching process (or tracer flushing stage), suggesting alternation of soil permeability during such a process switching, probably due to clay dispersion and swelling.

(2) For the breakthrough process, the Fickian transport was evident from the increased pattern of $\beta$ values towards 2.00 in the CTRW model, $\lambda$ value close to 2.0 in the FADE model, smaller values of $\omega$ in the TRM model, and a generally satisfactory fit of ADE with the experimental data.

(3) For the leaching process, the non-Fickian transport was noted by the smaller values of $\beta$ and $\lambda$ (much less than 2.00) in the CTRW and FADE models, respectively, and generally poor fitting of the experimental data using ADE and TRM.

(4) For better understanding the transport behavior in LPPM such as clay, it is important to analyze data from both the breakthrough process and leaching process.

\section{Conflicts of Interest}

The authors declare that they have no conflicts of interest.

\section{Acknowledgments}

This research was partially supported by the National Natural Science Foundation of China (Grant nos. 41372253, 41521001) and the Fundamental Research Funds for the Central Universities, China University of Geosciences (Wuhan) (Grant no. CUG140503). The authors sincerely thank Dr. Brain Berkowitz and Dr. Yunwu Xiong for the critical discussion on the initial version of this manuscript and David Weldon for his editing of this paper.

\section{References}

[1] C. E. Neuzil, "How permeable are clays and shales?" Water Resources Research, vol. 30, no. 2, pp. 145-150, 1994.

[2] G. Van der Kamp, "Methods for determining the in situ hydraulic conductivity of shallow aquitards-an overview," Hydrogeology Journal, vol. 9, no. 1, pp. 5-16, 2001.

[3] J. Li, X. Liang, M. Jin, G. Xiao, J. He, and Y. Pei, "Geochemistry of clayey aquitard pore water as archive of paleo-environment, western Bohai Bay," Journal of Earth Science, vol. 26, no. 3, pp. 445-452, 2015.

[4] A. J. Alrubaye, M. Hasan, and M. Y. Fattah, "Improving geotechnical characteristics of kaolin soil using silica fume and lime," Special Topics \& Reviews in Porous Media, vol. 7, no. 1, pp. 7785, 2016.

[5] E. Bani-Hani, F. Al-Khatib, and K. Khanafer, "Analysis of variants within different models of diesel oil volatilization process using various soil materials," Special Topics and Reviews in Porous Media, vol. 6, no. 3, pp. 261-266, 2015.

[6] H. H. Gerke and J. M. Köhne, "Dual-permeability modeling of preferential bromide leaching from a tile-drained glacial till agricultural field," Journal of Hydrology, vol. 289, no. 1-4, pp. 239-257, 2004.

[7] L. Gongsheng, C. Jin, Y. De, L. Hongliang, and L. Jijun, “Onedimensional equilibrium model and source parameter determination for soil-column experiment," Applied Mathematics and Computation, vol. 190, no. 2, pp. 1365-1374, 2007.

[8] L. F. Konikow, L. L. August, and C. I. Voss, "Effects of clay dispersion on aquifer storage and recovery in coastal aquifers," Transport in Porous Media, vol. 43, no. 1, pp. 45-64, 2001.

[9] J. Guimerà and J. Carrera, "A comparison of hydraulic and transport parameters measured in low-permeability fractured media," Journal of Contaminant Hydrology, vol. 41, no. 3-4, pp. 261-281, 2000.

[10] A. J. Guswa and D. L. Freyberg, "Slow advection and diffusion through low permeability inclusions," Journal of Contaminant Hydrology, vol. 46, no. 3-4, pp. 205-232, 2000.

[11] H. S. Ozturk and I. Ozkan, "Solute movement in large soil columns under different water flow velocities," Bodenkultur, vol. 53, no. 4, pp. 183-190, 2002.

[12] P. A. Hsieh and J. R. Freckleton, "Documentation of a computer program to simulate horizontal-flow barriers using the U.S. 
geological survey's modular three-dimensional finite-difference ground-water flow model," U.S. Geol. Survey Open-File Report, vol. 32, pp. 92-477, 1993.

[13] P. T. Harte, L. F. Konikow, and G. Z. Hornberger, "Simulation of solute transport across low-permeability barrier walls," Journal of Contaminant Hydrology, vol. 85, no. 3-4, pp. 247-270, 2006.

[14] S. W. Chapman, B. L. Parker, T. C. Sale, and L. A. Doner, “Testing high resolution numerical models for analysis of contaminant storage and release from low permeability zones," Journal of Contaminant Hydrology, vol. 136-137, pp. 106-116, 2012.

[15] J. C. Chambon, P. J. Binning, P. R. Jørgensen, and P. L. Bjerg, “A risk assessment tool for contaminated sites in low-permeability fractured media," Journal of Contaminant Hydrology, vol. 124, no. 1-4, pp. 82-98, 2011.

[16] Z. Li, Q. Xue, T. Katsumi, and T. Inui, "Electric-hydraulicchemical coupled modeling of solute transport through landfill clay liners," Applied Clay Science, vol. 101, pp. 541-552, 2014.

[17] F. J. Leij and S. A. Bradford, "Colloid transport in dual-permeability media," Journal of Contaminant Hydrology, vol. 150, pp. 65-76, 2013.

[18] G. L. Barns, S. F. Thornton, and R. D. Wilson, "Identification of small-scale low and high permeability layers using single well forced-gradient tracer tests: Fluorescent dye imaging and modelling at the laboratory-scale," Journal of Contaminant Hydrology, vol. 172, pp. 84-99, 2015.

[19] C. E. Neuzil, "Groundwater Flow in Low-Permeability Environments," Water Resources Research, vol. 22, no. 8, pp. 1163-1195, 1986.

[20] T. J. Ballard, S. P. Beare, and T. A. Lawless, "Fundamentals of shale stabilization: water transport through shales," SPE Formation Evaluation, vol. 9, no. 2, pp. 129-134, 1994.

[21] E. Bresler, "Transport of salts in soils and subsoils," Agricultural Water Management, vol. 4, no. 1-3, pp. 35-62, 1981.

[22] M. T. van Genuchten and P. J. Shouse, "Solute transport in heterogeneous field soils," Intermedia Pollutant Transport, pp. 177-187, 1989.

[23] G. Margolin and B. Berkowitz, "Continuous time random walks revisited: first passage time and spatial distributions," Physica A. Statistical Mechanics and Its Applications, vol. 334, no. 1-2, pp. 46-66, 2004.

[24] B. Berkowitz, A. Cortis, M. Dentz, and H. Scher, "Modeling Non-fickian transport in geological formations as a continuous time random walk," Reviews of Geophysics, vol. 44, no. 2, Article ID RG2003, 2006.

[25] F. J. Jiménez-Hornero, J. V. Giráldez, A. Laguna, and Y. Pachepsky, "Continuous time random walks for analyzing the transport of a passive tracer in a single fissure," Water Resources Research, vol. 41, no. 4, pp. 1-5, 2005.

[26] B. Berkowitz, J. Klafter, R. Metzler, and H. Scher, "Physical pictures of transport in heterogeneous media: advectiondispersion, random-walk, and fractional derivative formulations," Water Resources Research, vol. 38, no. 10, p. 1911, 2002.

[27] G. Huang, Q. Huang, and H. Zhan, "Evidence of one-dimensional scale-dependent fractional advection-dispersion," Journal of Contaminant Hydrology, vol. 85, no. 1-2, pp. 53-71, 2006.

[28] Y. Xiong, G. Huang, and Q. Huang, "Modeling solute transport in one-dimensional homogeneous and heterogeneous soil columns with continuous time random walk," Journal of Contaminant Hydrology, vol. 86, no. 3-4, pp. 163-175, 2006.
[29] P. Chakraborty, M. M. Meerschaert, and C. Y. Lim, "Parameter estimation for fractional transport: a particle-tracking approach," Water Resources Research, vol. 45, no. 10, Article ID W10415, 2009.

[30] B. W. Kuntz, K. Singha, S. Rubin, and B. Berkowitz, "Quantifying solute transport at the shale hills critical zone observatory," Vadose Zone Journal, vol. 10, no. 3, pp. 843-857, 2011.

[31] A. J. Desbarats, "Macrodispersion in sand-shale sequences," Water Resources Research, vol. 26, no. 1, pp. 153-163, 1990.

[32] D. H. Cumbie and L. D. McKay, "Influence of diameter on particle transport in a fractured shale saprolite," Journal of Contaminant Hydrology, vol. 37, no. 1-2, pp. 139-157, 1999.

[33] M. Bromly and C. Hinz, "Non-fickian transport in homogeneous unsaturated repacked sand," Water Resources Research, vol. 40, Article ID W07402, 2004.

[34] M. T. van Genuchten and P. J. Wierenga, "Mass transfer studies in sorbing porous media I. Analytical solutions," Soil Science Society of America Journal, vol. 40, no. 4, pp. 473-480, 1976.

[35] W. J. Bond and P. J. Wierenga, "Immobile water during solute transport in unsaturated sand columns," Water Resources Research, vol. 26, no. 10, pp. 2475-2481, 1990.

[36] I. Y. Padilla, T.-C. J. Yeh, and M. H. Conklin, "The effect of water content on solute transport in unsaturated porous media," Water Resources Research, vol. 35, no. 11, pp. 3303-3313, 1999.

[37] N. Toride, M. Inoue, and F. J. Leij, "Hydrodynamic dispersion in an unsaturated dune sand," Soil Science Society of America Journal, vol. 67, no. 3, pp. 703-712, 2003.

[38] F. Tatti, M. P. Papini, M. Raboni, and P. Viotti, "Image analysis procedure for studying Back-Diffusion phenomena from lowpermeability layers in laboratory tests," Scientific Reports, vol. 6, Article ID 30400, 2016.

[39] A. Cortis and B. Berkowitz, "Anomalous transport in "classical" soil and sand columns," Soil Science Society of America Journal, vol. 68, no. 5, pp. 1539-1548, 2004.

[40] D. A. Benson, S. W. Wheatcraft, and M. M. Meerschaert, "Application of a fractional advection-dispersion equation," Water Resources Research, vol. 36, no. 6, pp. 1403-1412, 2000.

[41] D. A. Benson, S. W. Wheatcraft, and M. M. Meerschaert, "The fractional-order governing equation of Lévy motion," Water Resources Research, vol. 36, no. 6, pp. 1413-1423, 2000.

[42] Y. Pachepsky, D. Benson, and W. Rawls, "Simulating scaledependent solute transport in soils with the fractional advective-dispersive equation," Soil Science Society of America Journal, vol. 64, no. 4, pp. 1234-1243, 2000.

[43] L. Zhou and H. M. Selim, "Application of the fractional advection-dispersion equation in porous media," Soil Science Society of America Journal, vol. 67, no. 4, pp. 1079-1084, 2003.

[44] F.-X. Chang, J. Chen, and W. Huang, "Anomalous diffusion and fractional advection-diffusion equation," Acta Physica Sinica, vol. 54, no. 3, pp. 1113-1117, 2005.

[45] X. Zhang, J. W. Crawford, L. K. Deeks, M. I. Stutter, A. G. Bengough, and I. M. Young, "A mass balance based numerical method for the fractional advection-dispersion equation: theory and application," Water Resources Research, vol. 41, no. 7, Article ID W07029, 2005.

[46] E. W. Montroll and G. H. Weiss, "Random walks on lattices. II," Journal of Mathematical Physics, vol. 6, pp. 167-181, 1965.

[47] H. Scher and M. Lax, "Stochastic transport in a disordered solid. I. Theory," Physical Review. B. Solid State, vol. 7, no. 10, pp. 44914502, 1973. 
[48] B. Berkowitz, H. Scher, and S. E. Silliman, "Anomalous transport in laboratory-scale, heterogeneous porous media," Water Resources Research, vol. 36, no. 1, pp. 149-158, 2000.

[49] M. Levy and B. Berkowitz, "Measurement and analysis of nonfickian dispersion in heterogeneous porous media," Journal of Contaminant Hydrology, vol. 64, no. 3-4, pp. 203-226, 2003.

[50] B. Berkowitz and H. Scher, "Exploring the nature of nonFickian transport in laboratory experiments," Advances in Water Resources, vol. 32, no. 5, pp. 750-755, 2009.

[51] V. Ciriello, A. Guadagnini, V. Di Federico, Y. Edery, and B. Berkowitz, "Comparative analysis of formulations for conservative transport in porous media through sensitivity-based parameter calibration," Water Resources Research, vol. 49, no. 9, pp. 5206-5220, 2013.

[52] B. Berkowitz and H. Scher, "Theory of anomalous chemical transport in random fracture networks," Physical Review E, vol. 57, no. 5, pp. 5858-5869, 1998.

[53] G. Kosakowski, B. Berkowitz, and H. Scher, "Analysis of field observations of tracer transport in a fractured till," Journal of Contaminant Hydrology, vol. 47, no. 1, pp. 29-51, 2001.

[54] G. Gao, H. Zhan, S. Feng, G. Huang, and X. Mao, "Comparison of alternative models for simulating anomalous solute transport in a large heterogeneous soil column," Journal of Hydrology, vol. 377, no. 3-4, pp. 391-404, 2009.

[55] K. Liu, Z. Wen, X. Liang, H. Pan, and J. Liu, "One-dimensional column test for non-Darcy flow in low permeability media," Chinese Journal of Dynamics, vol. 28, no. 1, pp. 81-97, 2013 (Chinese).

[56] C. Fallico, F. Chidichimo, and S. Straface, "Solute dispersion in porous media at different transport velocities and distances," International Water Technology Journal, vol. 2, pp. 100-109, 2012.

[57] M. Inoue, J. Šimůnek, S. Shiozawa, and J. W. Hopmans, "Simultaneous estimation of soil hydraulic and solute transport parameters from transient infiltration experiments," Advances in Water Resources, vol. 23, no. 7, pp. 677-688, 2000.

[58] M. U. Igboekwe and C. Amos-Uhegbu, "Fundamental approach in groundwater flow and solute transport modelling using the finite difference method," in Earth and Environmental Sciences, vol. 556 of InTech, chapter 13, pp. 301-328, Publishers Croatia, 2011.

[59] I. Shainberg, J. D. Rhoades, and R. J. Prather, "Effect of low electrolyte concentration on clay dispersion and hydraulic conductivity of a sodic soil," Soil Science Society of America Journal, vol. 45, no. 2, pp. 273-277, 1981.

[60] L. C. Goldenberg, M. Magaritz, and S. Mandel, "Experimental investigation on irreversible changes of hydraulic conductivity on the seawater-freshwater interface in coastal aquifers," Water Resources Research, vol. 19, no. 1, pp. 77-85, 1983.

[61] L. C. Goldenberg, M. Magaritz, A. J. Amiel, and S. Mandel, "Changes in hydraulic conductivity of laboratory sand-clay mixtures caused by a seawater-freshwater interface," Journal of Hydrology, vol. 70, no. 1-4, pp. 329-336, 1984.

[62] M. A. Maraqa, "Prediction of mass-transfer coefficient for solute transport in porous media," Journal of Contaminant Hydrology, vol. 53, no. 1-2, pp. 153-171, 2001.

[63] R. Haggerty, C. F. Harvey, C. Freiherr von Schwerin, and L. C. Meigs, "What controls the apparent timescale of solute mass transfer in aquifers and soils? A comparison of experimental results," Water Resources Research, vol. 40, Article ID W01510, 2004.
[64] M. Dentz, A. Cortis, H. Scher, and B. Berkowitz, "Time behavior of solute transport in heterogeneous media: Transition from anomalous to normal transport," Advances in Water Resources, vol. 27, no. 2, pp. 155-173, 2004. 

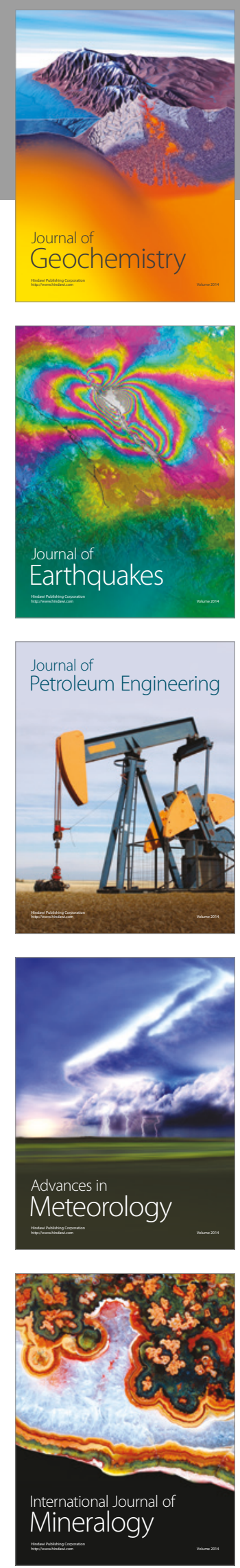
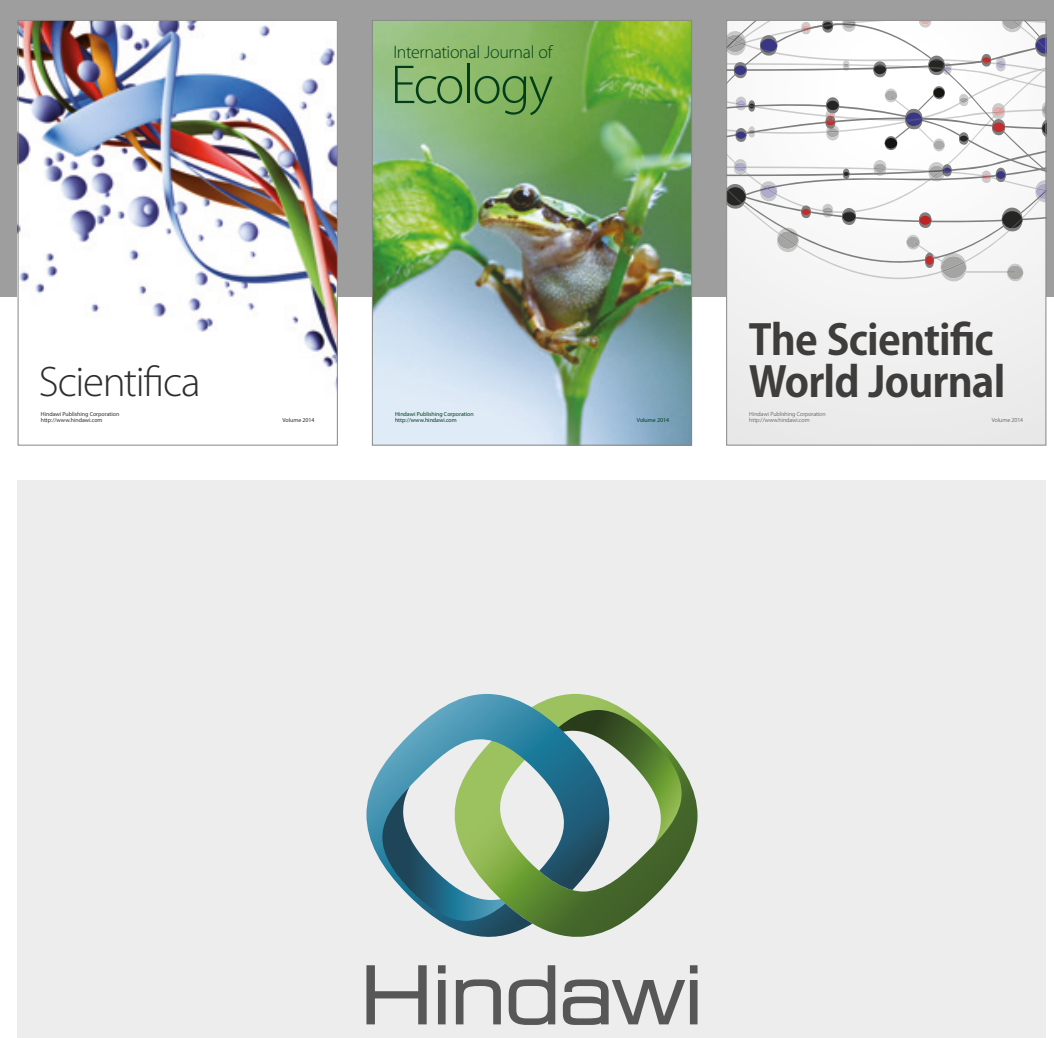

Submit your manuscripts at

https://www.hindawi.com
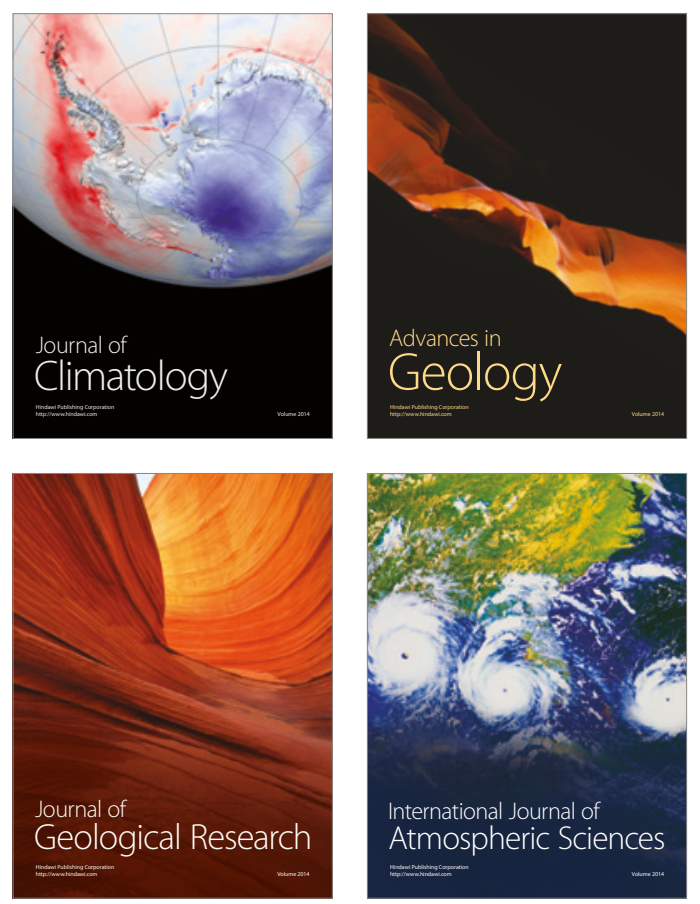

The Scientific

World Journal
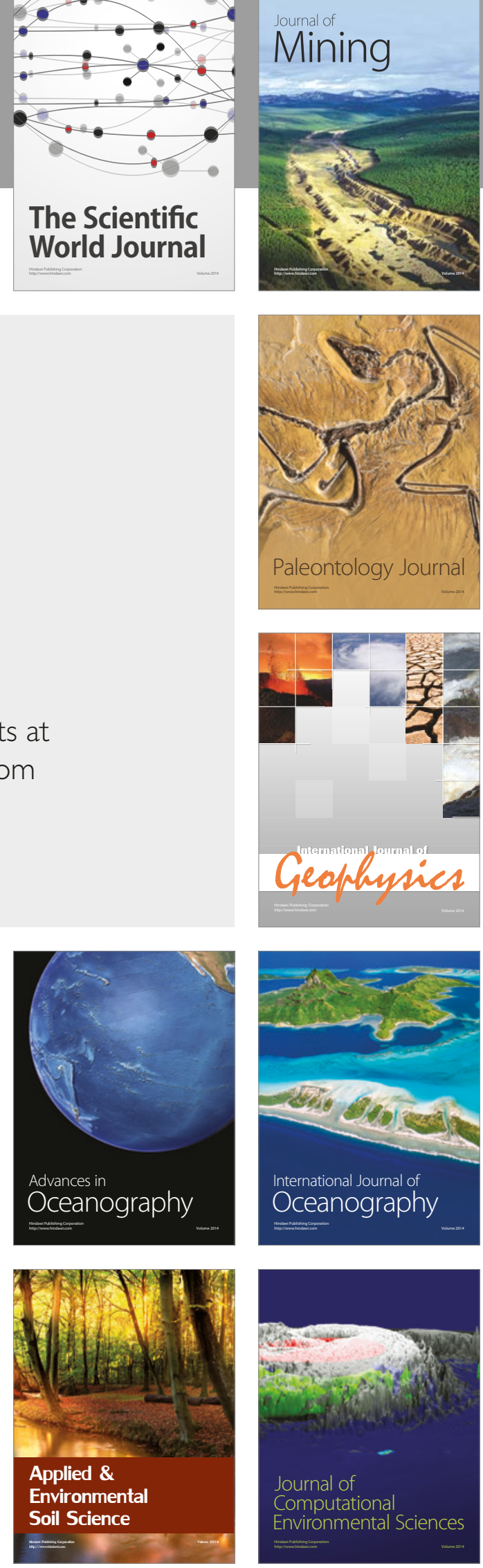